\title{
Wh-Questions: Linguistic Factors That Contribute to the Sequence of Acquisition ${ }^{1}$
}

\author{
Lois Bloom, Susan Merkin, and Janet Wootten \\ Teachers College, Columbia University
}

CitATiOn: Bloom, L., Merkin, S., \& Wootten, J. (1982). Wh-questions: Linguistic factors that contribute to the sequence of acquisition. Child Development, 53, 1084-1092. Reprinted in Bloom, L. (1991). Language development from two to three. New York: Cambridge University Press, pp. 242-256.

\begin{abstract}
The language development of 7 children was observed longitudinally from 2 to 3 years of age. The sequence in which these children learned to ask the forms of $w h$-questions with verbs was what, where, and who before how, why, and when, which is the same sequence that has been observed in other studies of the acquisition of first and second language. This sequence has been explained most often in terms of constraints on abstract thought in cognitive development. The purpose of the present study was to identify and describe other factors that contribute to the cognitive requirements for acquisition, and to examine how these factors covary developmentally with the meaning of the different $w h$-forms. Specifically, 3 kinds of linguistic constraints were observed to differentiate among wh-questions and contribute to their sequence of acquisition: (a) the syntactic functions of different $w h$-forms; (b) the selection of verbs in $w h$-questions; and (c) the use of $w h$-questions in discourse.
\end{abstract}

The sequence in which children learn to ask and answer questions with $w h$-forms has been explained most often as resulting from constraints on abstract thought in cognitive development (e.g., Ervin-Tripp, 1970; Fahey, 1942; Smith, 1933; Tyack \& Ingram, 1977). That is, the questions that are acquired late in the sequence, why and when, refer to more abstract, less tangible ideas than do what and where questions, which are learned first. However, recent studies of second language acquisition (e.g., Felix, 1976; Lightbown, 1978) have shown that older children learning to speak a second language acquire questions in the same developmental sequence as do children learning a first language at an earlier age. There are also experimental tests of children's comprehension of questions (Ervin-Tripp, 1970; Tyack \& Ingram, 1977) in which transitive and intransitive verbs influenced comprehension differentially with different $w h$-words. In addition, then, to the relative abstractness of the meaning of the different $w h$-forms that may contribute to their developmental sequence, there are other important linguistic factors that operate as well.

In the present study, several sources of influence on how and when children learn to ask $w h$-questions were investigated. Progress in the development of language depends upon the integration of semantics, syntax, and pragmatics (discourse) and integration of these specifically linguistic factors with nonlinguistic conceptual factors more generally (Bloom, 1976; Bloom, Lahey, Hood, Lifter, \& Fiess, 1980; Bloom, Miller, \& Hood, 1975). Such an integrative model is extended here to a new linguistic form, wh-questions, because the only explanations for their acquisition that have been seriously offered consist of the reduction of linguistic development to a single

\footnotetext{
${ }^{1}$ This study was supported by Research Grant HD 03828 from the National Institute of Child Health and Development; Fellowship F1-MH-30,001 from the National Institute of Mental Health, United States Public Health Service; and Research Grant Soc 74-28126 from the National Science Foundation to Lois Bloom. The study was published originally in Child Development, 53, 1084-1092 (1982); reprinted in Bloom, L. (1991). Language development from two to three, New York: Cambridge University, pp. 242-256; and reformatted for this digital version with slight changes in organization and minor text editing. We thank Lois (Hood) Holzman for her participation in the early stages of data processing and Karin Lifter, Jane Monroe, Robert Wozniak, and Joanne Bitetti Capatides for their helpful advice. Preliminary reports of this study were presented to the biennial meeting of the Society for Research in Child Development, 1979, and to the Stanford Child Language Research Forum, 1980.
} 
dimension of thought (i.e., the trend from concrete to abstract thought), or to a single dimension of language structure (i.e., the sequential application of transformational rules of grammar (Brown, 1968). Both no doubt influence the acquisition of $w h$-questions, but together with each other as well as with still other aspects of language that are learned concurrently. An ultimate explanation of language development will depend upon an understanding of how different aspects of language come together for the child in the process of its acquisition. Accordingly, for the purposes of the present study, it was hypothesized that the $w h$-forms learned later in the sequence of acquisition would differ from the $w h$-forms learned early in the sequence in their (1) syntactic function relative to the rest of the question, (2) use with verbs that were semantically more complex, and (3) use in different discourse environments. A demonstration that acquiring the forms and structures of language is not reducible simply to one or another dimension of thought or language ought to contribute to understanding processes of education and remediation as well as processes of development.

\section{SUBJECTS AND PROCEDURES}

Seven children, three girls and four boys, were observed longitudinally from about 22 to 36 months of age, in their homes, in informal play sessions with their mothers and/or a familiar adult (investigator). Three of the children were observed for approximately eight hours every six seeks; four of the children were observed for approximately five hours every three weeks. They were the firstborn children of white, college-educated parents who lived in university communities in New York City. Their parents were native speakers of American English and their mothers were their primary caregivers. They were chosen as subjects with these qualifications in what turned out to be, in retrospect, a naive effort to come up with a 'homogeneous' population. Since parent education, birth order, and economic differences among children had been found to be sources of individual differences in speech and language in other studies, these were the minimal 'controls' that seemed feasible, at the time, to ensure that the children would be similar in their language learning. ${ }^{2}$

The children were each visited in their homes for approximately six or eight hours over several days, every three or six weeks. The visits occurred in the context of their daily activities and informal play with a familiar adult (the investigators) and, less often, with their mothers. The same or similar toys were brought to all the sessions, for the different children and for each child, in an effort to establish consistency in the home contexts among the children and over time. The observations were audio recorded, and the transcriptions included all speech by child and adult, along with descriptions of nonlinguistic context and behavior. 3

For each of the analyses reported here, the development of each of seven children (three girls and four boys) was examined separately in order to justify combining the data for a group result. Comparison of the results from the individual children assured their similarity to one another in their patterns of development, so that the data were combined with confidence. Given (1) the small number of subjects, (2) the variation among the subjects in frequency and duration of the observation sessions, and (3) the sometimes small number of question tokens per cell in one or another analysis, statistical determination of similarity among subjects would be specious. Where there were differences within the group, the individual trends are indicated. The data from seven children were combined on the basis of increase in average utterance length. For this purpose, mean length of utterance (MLU) was computed for each text from each child according to procedures modified from Brown (1973) and described in Bloom and Lahey (1978, p. 42). The texts were grouped into four MLU periods that corresponded, essentially, to the four MLU Stages II through V identified by Brown. The MLU ranged from 2.00 to 2.30 (mean - 2.14) in Period A, from 2.68 to 3.00 (mean $=2.83$ ) in Period B, from 3.37 to 3.64 (mean $=3.45$ ) in Period $\mathrm{C}$, and from 3.68 to $5.03($ mean $=4.55)$ in Period D. These periods are not discrete; they simply provide a developmental

\footnotetext{
2 NoTE. However, see Bloom (1992) for a later appraisal of this decision.

3 The procedures for data collection and transcription are described in greater detail in Bloom (1970, pp. 234-9). See also, Bloom, Lightbown, and Hood (1974) and conventions for transcription of child language recordings, App. A, in Bloom \& Lahey (1978). The transcriptions of four of the children are stored for access by other researchers in the Special Collections at the Gottesman Memorial Libraries, Teachers College, Columbia University; transcripts of the Peter data are also part of the CHILDES database, the Child Language Data Exchange System, Carnegie-Mellon University.
} 
index based on increasing utterance length that proved to be convenient for observing substantive changes in the acquisition of $w h$-questions.

The children asked a total of 7,877 wh-questions in the period from approximately 22 to 36 months of age. There were four major analyses performed on this corpus of questions. First, the relative frequencies of questions with different $w h$-words were observed, and their developmental sequence of acquisition was inferred from the average rank order of frequency in relation to average age of emergence for the seven children. Only the whforms that were used productively (with productivity defined as the use of at least three different questions with a particular $w h$-form) by at least five of the seven children were included in computing the rank order of emergence. In order to determine how the $w h$-questions learned early in the sequence differed from those learned later, the second analysis consisted of inspection of the questions to determine the syntactic function of the $w h$-question words, and the third analysis consisted of identifying the range and variation of verbs used with the different $w h$-question words.

Since the sequence of acquisition was found to co-vary with both syntactic and lexical (verb) factors, a fourth analysis was performed in order to explore the intersection of these factors with discourse. Three aspects of discourse were investigated: (1) the occurrence of ellipsis (i.e., the deletion of part or all of the question except the $w h$-word); (2) patterns of adjacency (i.e., questions occurring within approximately 30 sec of a prior utterance) and contingency (i.e., adjacent questions with a constituent or referent of a constituent that was shared with a prior adult utterance occurring within five previous turns in topic-related discourse); and (3) verb cohesion (i.e., the instances where the verb in a child question was the same verb as in the prior adult utterance). The criterion for contingency was based upon the results of an earlier study of the development of contingency relations in the children's discourse (Bloom, Rocissano, \& Hood, 1976). The interobserver reliability of the interpretive discourse analysis was assessed in a random sample of 51 questions; the percent agreement was .92 for adjacency, .88 for contingency, and .92 for verb cohesion.

For each of these analyses except syntactic function, two populations of $w h$-questions were identified: One consisted of all of the child's questions, and the second population was the subset of only those questions that included a verb; $72 \%$ of the $w h$-questions included a verb. There were two kinds of questions without verbs: incomplete questions (e.g., "What that?") and elliptical questions (e.g., "Why?" or "What block" in response to an utterance such as "Get the block").

\section{RESULTS}

\section{Developmental Sequence}

Two sequences of emergence were distinguished: a sequence for only the $w h$-questions that included verbs, and a sequence for all $w h$-questions with and without verbs. The order of acquisition of those questions that included verbs was where and what at average age 26 months, then $w h o$ at average age 28 months, then how at average age 33 months, and why at average age 35 months. Which, whose, and when questions occurred rarely, even at age 36 months when the study ended. The order of emergence for the total population of all $w h$-questions was quite similar, except that how emerged before who, because how occurred without verbs (e.g., "How 'bout this?”) several months before how appeared in questions with verbs. The only exception to the sequence of acquisition among the seven children was one child who learned what before where; the other children acquired what and where at the same time.

\section{Syntactic Function of Wh-Forms}

There were structural differences among the questions that were acquired sequentially. The first $w h$-forms that emerged with verbs, what, where, and who, are wh-pronominals that ask for the major sentence constituents that they replace. As such, they are relatively simple syntactically. For example, for the sentence "Peter ate a cookie," the wh-pronominals ask for the object constituent, what (cookie); the subject constituent, who (Peter); and the verb phrase constituent, what do (ate cookie). Similarly, for the sentence "That's a cookie," what asks for cookie, and for the sentences "The cookie's gone" or "The cookies are in the bag," where asks for gone or bag. 
In contrast, why, how, and when, which emerged later, are $w h$-sententials that do not replace major sentence constituents but, rather, ask for information that pertains to the semantic relations among all the constituents in a sentence. For example, for the sentence "Peter ate a cookie," the wh-sententials ask for why (Peter ate the cookie), how (Peter ate the cookie), or when (Peter ate the cookie). The answers to the $w h$-sententials specify a reason, a manner, or the time that the entire event encoded in the sentence occurs. And finally, which and whose are adjectival forms that specify something about an object constituent (which apple or whose car). Which and whose were used rarely, and neither form was productive in questions with verbs for any child over the course of the study. The sequence in which the $w h$-forms were acquired, then, reflected the relative syntactic complexity among the different $w h$-forms. The pronominal forms what, where, and who were learned before the sentential forms why, how, and when, which were learned before the adjectival forms which and whose.

The wh-pronominals what, where, and who can function as constituents of the copula (the forms of be, i.e., is, are, etc.) to ask for the identities of objects, places, and persons as in such questions as "What's this?" "Where's the girl?" and "Who's that?" These identifying questions are different from those which ask for a sentence constituent of a main verb (e.g., "What's Peter eating?” or "Who breaked that?"). When what questions first appeared, they overwhelmingly functioned as identifying questions with the copula and only much later asked for the object constituents of main verbs. Similarly, the children's early where questions asked for the locations of absent objects and persons in copular questions and only later asked about locations of objects and persons in questions in which where pronominalized the place constituent of verbs such as go and take. When who questions, which were acquired later, first appeared, they asked for both identities and sentence constituents (both subject and object), although they asked for constituents more frequently. Thus, in Period A, what and where questions were almost always identifying questions; in Period B, what, where, and who questions also asked for sentence constituents.

\section{Selective Distribution of Verbs with Wh-Forms}

Along with questions with the contracted and uncontracted copula (forms of be), a small group of verbs, do, go, and happen were the most frequent verbs that the children used. They seemed to stand in for other more descriptive verbs such as sing or fix and as such functioned as general, all-purpose pro-verbs. For example, one can do many things, such as fix, stir, shake, turn, jump, and throw, and talk about them with do, without naming them specifically. Similarly, one can go to many places, in many ways (e.g., leave, ride, walk, run, swim, fly, etc.), and talk about it with $g o$.

Table 1. Distribution of Descriptive Verbs and Pro-Verbs with Wh-Questions

\begin{tabular}{rcc|cc}
\hline & \multicolumn{2}{c|}{ Pro-Verbs } & Descriptive Verbs & \\
\cline { 2 - 5 } & Frequency & Proportion & Frequency & Proportion \\
\hline Where & 2,010 & .94 & 131 & .06 \\
What & 2,323 & .85 & 397 & .15 \\
Who & 165 & .63 & 96 & .37 \\
How & 69 & .49 & 72 & .51 \\
Why & 80 & .25 & 238 & .75 \\
Which & 10 & .42 & 14 & .58 \\
When & 4 & .31 & 9 & .69 \\
Whose & 7 & .78 & 2 & .22 \\
Total & 4,668 & .83 & 959 & .17 \\
\hline
\end{tabular}

The pro-verbs, then, are very general in reference: The pro-verb do can refer to activities in general, the proverb go can refer to locative actions in general, and happen can refer to completed actions or events in general. In 
contrast, other verbs are more narrow in reference: One can only sing or draw or fix a few things. Such verbs are also descriptive in that they specifically name activities, and, as a result, are more semantically complex than proverbs in that (1) they carry more information; (2) they involve more restrictions on the selection of other parts of the sentence (e.g., subject and object); and (3) they involve many more conditions for the appropriateness of their use (see Fillmore, 1971, for discussion of these factors of semantic complexity).

The $w h$-forms differed according to the frequencies with which they were used with either the semantically more complex descriptive verbs, or the more general copula and proverb forms: (1) what, where, and who questions, which accounted for approximately three-fourths of all the questions with verbs, occurred with the copula or with pro-verbs eight times out of 10; (2) why and how occurred most often with descriptive verbs (see Table 1).

The great majority of all $w h$-questions with verbs (.83) occurred with the small group of general, all-purpose proverbs (the copula, do, go, happen). However, the descriptive verbs that did occur were distributed selectively among the questions with different $w h$-forms. The $w h$-questions that were acquired later in the sequence were more likely to occur with descriptive verbs than with pro-verbs (except whose, which was infrequent). This was due only in part to the fact that the children learned more different descriptive verbs over time, since (1) all of the descriptive verbs that the children used in their questions were used in previous observation sessions in utterances that were not questions, and (2) developmentally, while the proportion of questions with descriptive verbs increased with $w h y$ (from .55 to .78), there was less increase with what (from .09 to .23), no increase at all with where or who, and a decrease with how (from .65 to .46). More important, there was a strong relationship between the syntactic function of the individual $w h$-forms and the semantic complexity of the verbs used with each form. The pronominal wh-forms that asked for sentence constituents (what, where, who) occurred predominantly with pro-verbs, whereas the sentential wh-forms (how, why, when) tended to be used with descriptive verbs primarily. Thus, the order of acquisition of $w h$ - forms and the kind and variety of verbs that occurred with the different $w h$-forms were co-varying factors. In addition, each of the descriptive verbs that each child used tended to occur with only one of the $w h$-question forms. The proportion of verbs used exclusively with only one $w h$-form ranged from .65 to .94 for the seven children (mean $=.774$ and $\mathrm{SD}=.089$ ).

In sum, the children learned to ask $w h$-questions with descriptive verbs with those $w h$-question forms that were acquired late in the developmental sequence. The verbs that the children used tended to be restricted in their occurrence to one of the $w h$-question forms.

\section{Discourse Adjustments with Wh-Questions}

The final analyses were concerned with the ways in which the children's $w h$-questions were related to preceding adult utterances in discourse contexts. Three kinds of discourse adjustments differentiated among the whquestions with development: verb deletion, linguistic contingency with constituent relations shared with a prior utterance, and verb cohesion where the child question repeated a verb from a prior adult utterance.

Verb Deletion. Wh-questions without verbs accounted for .28 of the children's questions overall and were of two kinds: (1) incomplete questions in which a verb would be obligatory in the adult language but was not used in the child's utterance, for example, "What that?" or "Where dog?” and (2) elliptical questions in which a verb

Table 2. Elliptical Verb Deletion in Questions

\begin{tabular}{lcccc}
\hline \multicolumn{5}{c}{ Proportion of All Wh-Questions } \\
\cline { 2 - 5 } & Period A & Period B & Period C & Period D \\
\hline Where & .01 & .02 & .07 & .15 \\
What & .03 & .07 & .19 & .34 \\
Who & .00 & .04 & .09 & .15 \\
How & $\mathrm{np}$ & .70 & .51 & .35 \\
Why & $\mathrm{np}$ & .89 & .74 & .36 \\
\hline
\end{tabular}

Note: $\mathrm{np}$ indicates how and why were not productive in Period A. 
would not be expected, for example, contingent questions such as "Why?" or "What?" or "What book?" in response to "Give me the book." Across all $w h$-forms, incomplete questions in which an obligatory verb did not occur decreased over time as utterance length increased and as the children learned more of the formal requirements for asking questions. At the same time, as can be seen in Table 2, there was a gradual increase in the occurrence of elliptical questions without verbs, but only for what, where, and who the earliest and most frequent questions the children asked). In contrast, the occurrence of how and why questions without verbs, where the verb was not obligatory, showed a decrease over time. The discourse adjustments that the children made then, with respect to whether a verb was expressed, were different for the different wh-forms; what, where, and who questions presented a pattern of increasing verb ellipsis or shortened utterance length; how and why questions presented a pattern of increasing expansion of utterance length with expression of nonobligatory verbs.

Linguistic Contingency. In order to further explore the selective occurrence of verbs with different $w h$-forms, a subset of the corpus of $w h$ - questions with verbs was examined for evidence of contingency on previous adult utterances in the discourse context. This subset consisted of only those questions with verbs that were adjacent to a prior utterance in connected discourse, by virtue of occurring within approximately 30 sec of the prior utterance: 812 questions that represented $14.4 \%$ of the children's 5,627 questions with verbs. (The 3,719 questions with the copula and the why don't questions asked by one of the children, which appeared to function as a

Table 3. Proportion of Adjacent Questions and Adjacent Questions that Were Contingent

\begin{tabular}{lcc|cc|cc}
\hline \multicolumn{7}{c}{ Mean Questions per Hour } \\
\cline { 2 - 7 } & $\begin{array}{c}\text { Period B } \\
(N=259)\end{array}$ & $\begin{array}{c}\text { Period C } \\
(N=212)\end{array}$ & & $\begin{array}{c}\text { Period D } \\
(N=40)\end{array}$ & \\
\cline { 2 - 7 } & Adjacent & Contingent & Adjacent & Contingent & Adjacent & Contingent \\
\hline Where & 1.47 & .46 & .74 & .19 & 2.14 & .75 \\
What & .90 & .33 & .89 & .27 & 1.82 & .64 \\
Who & .28 & .11 & .21 & .09 & .45 & .14 \\
How & .60 & .19 & .36 & .05 & .75 & .16 \\
Why & .23 & .06 & .28 & .13 & 1.07 & .57 \\
\hline
\end{tabular}

Note: There were no contingent questions in Period A.

directive to act rather than as true why questions, were not included in this analysis. An adjacent utterance was considered contingent if it maintained the topic of conversation and shared any constituent, or the referent of a constituent, with a prior adult utterance that occurred within five previous turns in connected discourse. The following examples are typical of the children's contingent questions with verbs:

(1) Adult: Let's see what I can find.

Child: What can you find?

(2) (Baby sister is crying)

Adult: Let's go see why she's crying. Maybe we can get her to stop crying.

Child (to baby): Why are you crying?

Adult: Why is she crying?

Child: Why is this baby crying?

(3) (Child and adult reading a story about swimming)

Adult: Why are they not coming?

Child: Why they not coming in the water? 
Because of the substantial differences among the $w h$-questions in relative frequency and the fact that observation sessions with the different children varied in duration from 5 to 8 hours, adjacency and contingency were computed in terms of the average rate of adjacent questions and the average rate of linguistically contingent questions per hour. There were too few contingent questions in Period A for this analysis; the contingency of questions began in Period B and increased in frequency from Period B through Period D.

Table 4. Proportion of Adjacent Questions per Hour that Were Contingent

\begin{tabular}{cc|c|c}
\hline & $\begin{array}{c}\text { Period B } \\
(N=259)\end{array}$ & $\begin{array}{c}\text { Period C } \\
(N=212)\end{array}$ & $\begin{array}{c}\text { Period D } \\
(N=341)\end{array}$ \\
\hline Where & .31 & .26 & .35 \\
What & .37 & .27 & .35 \\
Who & .39 & .41 & .30 \\
How & .32 & .15 & .21 \\
Why & .25 & .47 & .53 \\
\hline
\end{tabular}

Note: There were no contingent questions in Period A.

In terms of the rate of questions asked per hour, what and where questions were the most frequent questions and also presented the highest rates of adjacency and contingency, as seen in Table 3, averaged for the seven children. However, when considering the proportional rate of adjacent questions per hour that were contingent, why questions showed the highest proportion of linguistic contingency; how questions showed the lowest proportion of contingency; and only about one-third of the what, where, and who questions were contingent; see Table 4. In terms of the rate of questions asked per hour, then, given that a child asked any $w h$-question, it was most likely to be a what or where question, and given that a child asked a linguistically contingent question, it was still most likely to be a what or where question. But given that a child asked a why question, that question was more likely to be linguistically contingent than if the child were to ask any other kind of $w h$-question. Thus, why questions occurred most often with descriptive verbs and were also linguistically contingent more often than were questions with the other $w h$-forms. However, the relatively low frequency with which any of the $w h-$ forms were contingent indicated that the children's questions, in general, were more likely to introduce the topic of discourse (the noncontingent questions) than to produce a question in response to what someone else said.

Verb Cohesion. Because (1) why questions were proportionately more often contingent than the other whquestions and also occurred most frequently with descriptive verbs, and (2) each of the descriptive verbs occurred infrequently, it was hypothesized that the source of descriptive verbs in the children's $w h y$ questions might have

Table 5. Verb Cohesion: Repetition of Descriptive Verbs from Prior Adult Utterance

\begin{tabular}{cc|c|c}
\hline & \multicolumn{3}{c}{ Proportion of Contingent Questions with Descriptive Verbs } \\
\cline { 2 - 4 } & Period B $(N=87)$ & Period C $(N=139)$ & Period D $(N=280)$ \\
\cline { 2 - 4 } Where & .12 & .11 & .33 \\
What & .18 & .20 & .24 \\
Who & .18 & .21 & .27 \\
How & .20 & .09 & .17 \\
Why & $\mathrm{np}$ & .42 & .40 \\
\hline
\end{tabular}

Note: np indicates why was not productive in Period B.

been the prior adult utterances. All adjacent questions with descriptive verbs were examined for verb cohesion: the proportion of questions that repeated a verb from a prior adult utterance. When a verb was repeated, it was 
almost always an exact repetition (as in the examples of contingency), or else an inflected verb was repeated without its inflection.

The questions analyzed for verb cohesion were a subset of the questions analyzed for linguistic contingency, consisting only of those adjacent, linguistically contingent questions that occurred with descriptive verbs $(N=$ 506). The remaining questions $(N=306)$ that were also analyzed for linguistic contingency (reported in Tables 3 and contained the pro-verbs do, go, and happen. The results reported in Table 5 should be interpreted with some caution, since in some cells only one or two of the children contributed to a group mean. For all of the question forms except how, there was an increase in the extent to which children made use of descriptive verbs from the adult discourse context. Further, why questions shared the adult verb more frequently than any other wh-question, but still only about .40 of the time. How questions, on the other hand, with the second most frequent use of descriptive verbs, displayed the least amount of verb cohesion with prior adult utterances in the last two MLU periods. Thus, verb cohesion was greatest with why questions, which were also most often linguistically contingent, indicating that the source of linguistic contingency was often the verb in the prior adult utterance.

\section{DISCUSSION}

The children in this study learned to ask $w h$-questions in the same developmental sequence - what, where, and who questions were learned before why, how, and when questions - as has been reported in previous studies of first language acquisition (e.g., Brown, 1968; Ervin- Tripp, 1970; Labov \& Labov, 1976; Lewis, 1938; Smith, 1933) and second language acquisition (e.g., Felix, 1976; Lightbown, 1978). Cognitive complexity has been cited most often as the factor responsible for determining the sequence in which children learn $w h$-questions. However, the cognitive hypothesis as it has been presented so far in the literature has been concerned only with the polarity of concrete and abstract thought. As such, it is only a post hoc explanation that is, as yet, unsupported by independent evidence, and in fact, there is evidence to dispute it. First, children who learn a second language at age 5 or 6 acquire $w h$-questions in the same order as has been observed in first language learning (Lightbown, 1978). The capacity for relative abstract thought could not be the only factor that determines sequence of acquisition in a second language for a 5-year-old child who already has the conceptual ability to ask all of the same questions in the first language.

Of greater relevance to the present study, however, is the fact that the conceptual notions that are encoded by later appearing questions, time (when) and causality (why), were encoded reliably at an earlier age in other linguistic structures that these same children learned. Specifically, in the acquisition of complex sentences with syntactic connectives reported in Bloom, Lahey, Hood, Lifter, Fiess (1980), causally interpretable relations were encoded with and, because, and/or so before the children asked why questions, and temporal relations were encoded with and then, and when long before the children asked when questions. In fact, causal and temporal interclausal meaning relations and the syntactic connectives that encode them were among the most frequent meaning relations and connectives in the children's complex sentences, beginning at about 26 months of age. Thus, these children had begun to know temporal and causal semantic notions but not for the syntax of $w h-$ questions; that is, a child can know something about semantics but still need to learn the particular syntax.

In the present study, a number of factors interacted with one another to determine the relative conceptual requirements of $w h$-questions and, as a result, their sequence of acquisition. At least three factors contributed to the linguistic complexity of $w h$-questions and helped to determine sequence of acquisition: the syntactic function of the individual $w h$-forms, the relative semantic complexity of different verbs, and contingency relations in discourse.

The earliest learned wh-question forms (what, where, who) were used overwhelmingly with the copula or the pro-verbs do and go. Since what, where, and who are wh-pronominals that stand for major sentence constituents, they could be combined with the copula and general pro-verbs such as do or go without the more complex semantic and syntactic requirements of more specific descriptive verbs. In contrast, why, how, and when, which were acquired later, are the $w h$-sententials that do not replace major sentence constituents; the scope of the meaning of these $w h$-forms was the sentence, and they were used with descriptive verbs primarily. 
Descriptive verbs tended to be used only in one or a few different $w$ h-questions, even though these same verbs were used more freely and productively in the children's nonquestion statements. The implication is that learning the meaning and syntax of individual verbs covaried with learning the meaning and syntax of the different $w h$ question forms.

The fact that descriptive verbs tended to occur infrequently, and only with one or another $w h$-question word, might have suggested that the children's questions were learned as routines. Certain of the children's early questions were most probably unanalyzed; that is, the $w h$ - word was not separable from the rest of the question in the child's view (e.g., "What's that?" "What X doing?" "What happened?" "Where X go?"). If why and how questions were also being learned in routines in the same way, then one might expect that they too would occur with only a few descriptive verbs used with great frequency (as do, happen, and the copula were used with what, for example). But they did not, which was taken as evidence that why and how with descriptive verbs were not learned as routines in the same way as early questions with what and where might have been.

Another possibility was that there were many different, but infrequent, descriptive verbs with why and how because the children were repeating these verbs from prior adult utterances and thereby learning why and how with descriptive verbs in discourse routines. However, why and how differed from each other in their relation to prior adult utterances, so that the same explanation for the use of descriptive verbs would not apply to both. The children were learning to ask $w h y$ questions with many descriptive verbs, in the context of contingency relations with the prior adult utterance, and they repeated the verb from the adult utterance about $40 \%$ of the time. However, a large number of descriptive verbs occurred with how, but how questions rarely repeated a prior verb, indicating that the children were not depending only upon the linguistic context for the source of their use of descriptive verbs. It appears, then, that shared verbs in discourse is only a part of the explanation of the differential occurrence of descriptive verbs with $w h$-forms. Why and how occurred most often with descriptive verbs but functioned differently in discourse: Why questions were responsive to topics initiated by someone else; that is, they were contingent; how questions introduced new topics.

In an earlier study of the development of discourse skills (Bloom, Rocissano, \& Hood, 1976), linguistic contingency was observed to increase developmentally between 2 and 3 years of age, but linguistically contingent questions were a late development. In the present study, child questions were contingent less than half the time, and only the contingency of why questions increased developmentally. Thus, these children were most likely to ask a question with a topic of their own, and the ability to use the topic of a prior utterance for formulating a responsive question had only begun to develop during the time period of this study.

Several aspects of the results reported await further investigation of still other factors, most notably contextual and other pragmatic factors, that contributed to the sequence of development of the two groups of $w h$-questions: what, where, and who before how, why, and when. For example, it is not clear, from the present data, why who questions emerged later than what and where and why when questions emerged later than how and why. One possible explanation is the relative frequency of contextual events in which children would hear and have occasion to use who and when questions. For example, young children are usually in the company of familiar others. There are many more objects and places than persons they could ask about which might have contributed both to the late appearance of $w h o$ and the fact that there were relatively fewer identifying questions with $w h o$ than questions that asked for sentence constituents (compared with what and where).

To conclude, the results of the present study emphasize linguistic complexity and, in particular, the semanticsyntactic functions of verbs as major factors that contributed to the sequence of acquisition of $w h$ - forms (see Bloom, 1981). Children learn to ask $w$ h-questions in a particular order, but in the context of learning the syntactic function of $w h$-words, the syntax and semantics of verbs, and the requirements of discourse. Such linguistic factors as these, together with other conceptual and pragmatic factors, determine the cognitive requirements for learning $w h$-questions. 


\section{REFERENCES}

Bloom, L. (1970). Language development: Form and function in emerging grammars. Cambridge, MA: MIT Press.

Bloom, L. (1976). An integrative perspective on language development. Keynote address. In Papers and reports on child language development (No. 12, pp. 1-22). Department of Linguistics, Stanford University.

Bloom, L. (1981). The importance of language for language development: Linguistic determinism in the 1980 . In H. Winitz (Ed.), Native language and foreign language acquisition (vol. 379, pp. 160-71). New York: New York Academy of Sciences.

Bloom, L. (1992). Racism in developmental research. President's Message, Division 7 Newsletter. Washington, DC: American Psychological Association, Fall-Winter.

Bloom, L., \& Lahey, M. (1978). Language development and language disorders. New York: John Wiley.

Bloom, L., Lahey, M., Hood, L., Lifter, K., \& Fiess, K. (1980). Complex sentences: Acquisition of syntactic connectives and the semantic relations they encode. Journal of Child Language, 7, 235-61.

Bloom, L., Lightbown, P., \& Hood, L. (1975). Structure and variation in child language. Monographs of the Society for Research in Child Development, 40 (Serial no. 160).

Bloom, L., Miller, P., \& Hood, L. (1975). Variation and reduction as aspects of competence in language development. In A. Pick (Ed.), Minnesota symposia on child psychology (vol. 9, pp. 3-55). Minneapolis: University of Minnesota Press.

Bloom, L., Rocissano, L., \& Hood, L. (1976). Adult-child discourse: Developmental interaction between information processing and linguistic knowledge. Cognitive Psychology, 8, 521-52.

Brown, R. (1968). The development of wh-questions in child speech. Journal of Verbal Learning and Verbal Behavior, 7, 279-90.

Brown, R. (1973). A first language, the early stages. Cambridge, MA: Harvard University Press.

Ervin-Tripp, S. (1970). Discourse agreement: How children answer questions. In J. Hayes (Ed.), Cognition and the development of language (pp. 79-107). New York: Wiley.

Fahey, G. (1942). The questioning activity of children. Journal of Genetic Psychology, 6o, 337-57.

Felix, S. (1976). Wh-pronouns and second language acquisition. Linguistische Berichte, 44, 52-64.

Fillmore, C. (1971). Deixis, I. Unpublished lectures.

Labov, W., \& Labov, T. (1976). Learning the syntax of questions. In R. Campbell \& P. Smith (Eds.), Recent advances in the psychology of language: Formal and semantic approaches (pp. 1-44). New York: Plenum.

Lewis, M. M. (1938). The beginning and early functions of questions in a child's speech. British Journal of Educational Psychology, 8, 150-71.

Lightbown, P. (1978). Question form and question function in the speech of young French L2 learners. In M. Paradis (Ed.), Aspects of bilingualism (pp. 21-43). Columbia, SC: Hornbeam.

Smith, M. (1933). The influence of age, sex and situation on the frequency, form and function of questions asked by preschool children. Child Development, 4, 201-381.

Tyack, D., \& Ingram, D. (1977). Children's production and comprehension of questions. Journal of Child Language, 4, 211-24. 